\title{
MORTE E GÊNERO EM SÊNECA: UM DIÁLOGO COM OS VESTÍGIOS DA CULTURA MATERIAL
}

\author{
Luciane Munhoz de Omena* \\ Margarida Maria de Carvalho*
}

RESUMO: O presente artigo visa à compreensão das relações estabelecidas entre morte e gênero nas representaçôes filosóficas de Lúcio Aneu Sêneca, bem como a presença de tais relaçóes na cultura material; para tanto serão utilizadas Epistulae Morales e Ad Marciam de Consolatione. A partir daí, traçaremos algumas reflexōes críticas acerca dos comportamentos femininos aristocráticos em relação ao luto prolongado e, dessa forma, analisando a prática da uirtus, compreender a criação de normas de conduta feminina para a expressão pública da dor e a inserção de dimensões mais particulares e emocionais no modo como se lembravam dos mortos na corte imperial romana.

PALAVRAS-CHAVE: Morte, Feminino, Luto, Roma, Virtude.

\section{DEATH AND GENDER IN SENECA: A DIALOGUE WITH THE VESTIGES OF THE MATERIAL CUTURE}

* Professora Adjunta de História Antiga da Universidade Federal de Goiás \Brasil. Pósdoutoranda no Instituto de Filosofia e Ciências Sociais \UNICAMP sob a supervisão do Prof. Dr. Pedro Paulo A. Funari. Bolsista CAPES. E-mail: lucianemunhoz34@gmail. com

** Professora Assistente MS3-2 de História Antiga do Departamento de História e Programa de Pós-graduação em História da UNESP

- Franca $\backslash$ Brasil. Coordenadora do Grupo do Laboratório de Estudos sobre o Império Romano da mesma instituição. Doutora em História Antiga pela USP.

\begin{abstract}
This article aims the understanding of the relationships set between death and gender in the philosophical logos of Lucius Annaeus Seneca, as well as the presence of such relationships in the material culture; in order to do so, Epistulae Morales and Ad Marciam de Consolatione will be used. From there, we will make some critial reflections on the feminine aristocratic behaviour regarding prolonged mourning, thus, by analysing the practice of virtus, we wil understand the creation of behavioural feminine rules to the public expression of pain and the insertion of more particular and emotional dimensions in the way they reminded of the dead in the Roman imperial court.
\end{abstract}

KEYWORDS: Death, Feminine, Mourning, Rome, Virtue. 


\title{
INTRODUÇĀO
}

\begin{abstract}
"Annum feminis ad lugendum constituere majores; non ut tam diu lugerent, sed ne diutius; viris nullum legitimum tempus est, quia nullum honestum. Quam tamen mihi ex illis mulierculis dabis, vix retractis a rogo, vix a cadavere revulsis, cui lacrymae in totum mensem duraverint? Nulla res citius venit in odium, quam dolor: qui recens, consolatorem invenit, et aliquos ad se adducit; inveteratus vero deridetur. Nec immerito; aut enim simulatus, aut stultus est" (Sêneca. Epistulae Morales 63. 13).
\end{abstract}

A epígrafe supracitada evidencia o lamento do filósofo, que, em algumas circunstâncias, mulheres da corte romana, dominadas pelo sofrimento, expressos nos gestos de luto, tornavam indignos seus comportamentos. A exteriorização excessiva da dor, atribuída à feminilidade dos ritos tradicionais de luto revelava uma construção normativa de uma moralidade aristocrática (ERKER, 2011, p. 42). Segundo Sêneca, a preocupação dos agentes da dor não deveria ser somente com a condição post mortem daquele que faleceu, mas também com os sentimentos dos que ficavam vivos. $\mathrm{O}$ ritual fúnebre significava, portanto, em suas palavras, a elaboração do luto.

Como podemos observar, temas relacionados à morte $\mathrm{e}$ ao sentido da vida, em determinadas sociedades, podem ser compreendidos pelas crenças registradas pelas documentações textuais (e.g. literária, filosófica, histórica, biográfica), pelos

1. Os cenotáfios eram monumentos comemorativos sem o corpo, pois a tumba devia conter os restos mortais do falecido. Nestes monumentos aparecem, com maior frequência, celebrações de mortos em batalhas; logo suas representações em estátuas, relevos, retratos e moedas tornavam-se simulacros e substituíam, dessa forma, o cadáver (YÉBENES, 2009, p. 50). monumentos funerários, pelos cenotáfios ${ }^{1}$, pelos rituais de sepultamento e demais formas de cultuar à morte. Os rituais funerários dizem muito sobre como o homem se sente em relação à morte, e, ao mesmo tempo, sugerem uma função social preservada ao longo do tempo e das gerações.

É nesse sentido que as diversas documentaçōes sobre o Império Romano nos oferecem um modo bastante peculiar de pensar a nossa relação com a morte. Dessa forma, tal material faz com que os processos de preservação, armazenamento e a relação intrínseca entre memória e esquecimento, nos conduzam a pensar que sua produção e seus usos sociais, destinam-se, em algumas situações, às construções de identidades pessoais, familiares, étnicas, feminina e masculina da sociedade romana. Ora, essa memória é articulada, no presente, aos 
processos de recriação de imagens do passado, pois tal como entende Roller (2009, p. 216), as imagens vinculam-se à produção de um passado para orientar o momento atual, partindo da elaboração dos exempla. Tudo isso ocorre à medida que as açôes passadas podem se reproduzir no tempo presente. $\mathrm{O}$ interesse pelo passado não é meramente histórico, pois os espaços do lembrar dependem das condiçôes sociais e culturais (Ver ainda: ECKARDT \& WILLIAMS, 2003; ASSMANN, 2011; OMENA \& FUNARI, 2012), englobando a produção de uma memória social articulada em torno de um passado comum, logo:

O uso ideológico da memória era promover o que foi considerado digno de lembrança. A vida pública romana estava enraizada nas memórias do passado. Decidir quem ou o que seria lembrado, e como, foi um aspecto de poder e autoridade, o presente poderia ser definido e justificado por referência e controle do passado (HOPE a, 2003, p. 115).

Como já demos a entender, ao citarmos os tipos de documentação existente para o estudo da morte, a promoção dos indivíduos e sua póstuma memória encontravam-se em diversos recursos estratégicos como moedas, monumentos arquitetônicos, arte funerária, narrativas textuais, as quais contribuíam para a construção da reputação do indivíduo na sociedade romana. Sendo assim, faz-se necessário compreender a associação entre memória, escrita e morte em função de sua não dissociabilidade. Tal como formula Gagnebin, túmulo e palavra coadjuvam no trabalho de memória "que, justamente, por se fundar na luta contra o esquecimento, é também o reconhecimento implícito da força deste último: o reconhecimento do poder da morte" (GAGNEBIN, 2006, p. 45). A produção e a transmissão de memória fundam-se, sobretudo, no temor pela morte social, no processo de esquecimento, que implica, em outras palavras, tornar-se um sem nome no mundo dos vivos (VERNANT, 2001, p. 88).

Em razão disso, os monumentos funerários e os epitáfios manifestavam, de modo efetivo, o desejo de perpetuação e transmissão das identidades associadas aos diversos aspectos da vida romana como as práticas de ofícios, a presença das carreiras públicas e, em especial, os laços familiares, que nos 
interessam mais particularmente. A própria localização dos túmulos na necrópole envolvia visibilidade, à medida que os monumentos de pedra revelavam atitudes e aspirações de cidadãos e não cidadãos romanos, pois, de fato, representavam um corte transversal visual não de todos os habitantes, mas de um coletivo diferenciado de indivíduos e grupos que intensificavam seus valores sociais na sociedade romana (CARROL, 2006, p. 04). Nesse percurso, Carrol propõe reflexões sobre as representaçôes familiares compostas, com frequência, por mãe, pai, crianças ou outros membros familiares, cuja busca por espaços privilegiados nas necrópoles, levava em consideração o aspecto físico e visível de memória. Segundo a própria autora:

Homens livres e aristocráticos utilizavam as gerações anteriores e, de maneira semelhante, escravos e libertos iniciavam suas histórias com a alforria, e, muito frequente, nomeavam ex-proprietários em epitáfios, os incorporando em seus relacionamentos sociais (CARROL, 2006, p. 39).

Como se observa, os monumentos funerários representavam símbolos de distinção e, dessa forma, transformavam-se em modelos sociais. Por exemplo, escravos, impedidos de se casarem legalmente, buscavam a liberdade para garantir, dentre outras prerrogativas, o nascimento livre de seus filhos (CARROLL, 2005, p. 39). Tais famílias escolhiam túmulos, epitáfios e, assim como analisa Huskinson em seu artigo - "Constructing childhood on Roman funerary memorials" (cf. KING, 2000; DIXON, 2001; GUNDERSON, 2003; BOATWRIGHT, 2005, entre outros) - grupos de relevos, que apareciam, de modo geral, em estilos repetitivos e homogêneos (retangulares, retratos esculpidos com figuras em pé ou drapeados com bustos frontais), mas que deveriam, seguir representações de homens, mulheres e crianças vestidas como cidadãos romanos (HUSKINSON, 2007, p. 325), à medida que apresentavam a toga, a palla e, em alguns casos, a bulla (amuleto utilizado por meninos pertencentes à aristocracia). Como acentua Huskinson (2007, p. 325):

Assim como todos os grupos socialmente aspirantes, esses libertos baseavam-se em iconografia usada por aristocratas em 
suas comemorações: representando bustos esculpidos aproximavam-se das práticas aristocráticas da época de Augusto.

Considerados memoriais, os túmulos podiam ser vistos por milhares de pessoas, e, dessa maneira, criava-se e conservava-se a memória dos mortos e de seus familiares. Tal como se observa no mausoléu de Caecilia Metella:

\section{Mausoléu de CaEcilia Metella $A^{4}$}

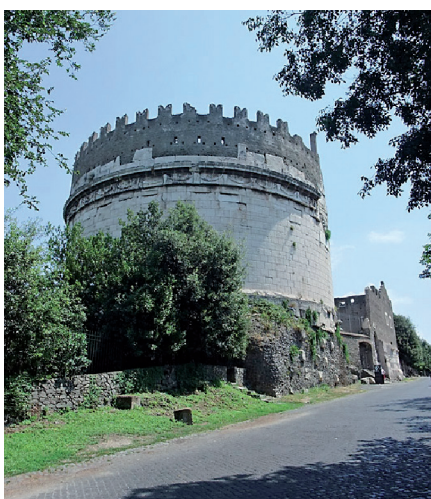

Figura I

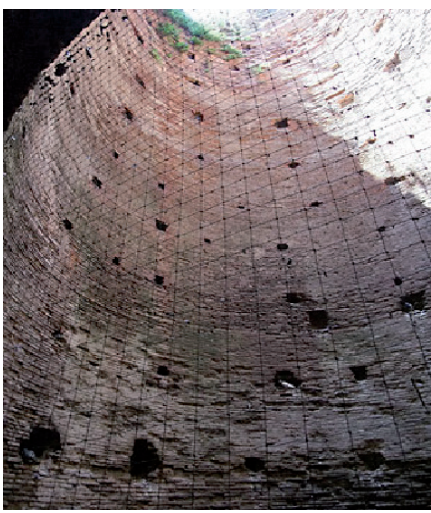

Figura III

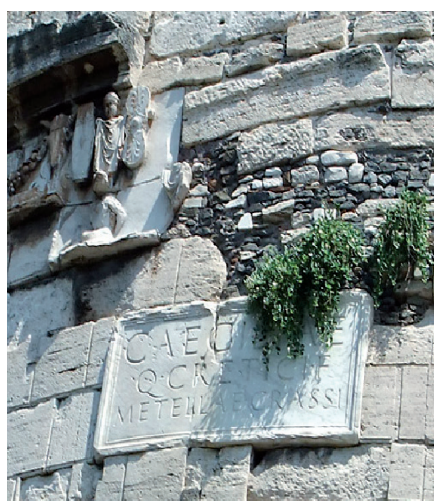

Figura II

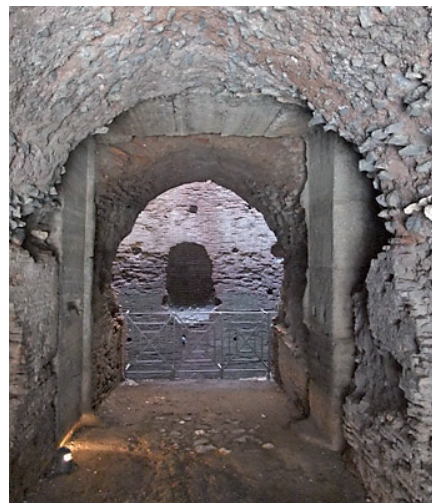

Figura IV

Com essas ressalvas, podemos considerar o mausoléu de Caecilia Metella um memorial que celebrava, com grande visibilidade, a sua família. Construído na Via Appia Antica, em Roma, no fim do período republicano, segue, de modo

4. As figuras I, II, III e IV são créditos de Ann Raia (2009), podendo ser consultadas na página: http://www.vroma.org/ cgibin/mfs/var/www/html/ images?link=/raia_images/ index $8 . h$ tml\&file $=$ / var/www/html/images/ raia_images/index 8 . html $\&$ line $=128 \# \mathrm{mfs}$. 
5. As informações acerca das medidas do mausoléu de Caecilia Metella foram retiradas do site - www.vroma. org.. Podemos consultar ainda: PATTERSON, 2000; CARROL, 2006; JOHANSON, 2011 entre outros mais.

6.Johanson em seu artigo - "A walk with the dead: a funerary cityscape of ancient Rome" - apresenta um interessante esquema que contempla a localização dos túmulos próximos ao mausoléu de Caecilia Metella. São eles: Horatii e Curiatii, tumba em forma de pirâmide, Gaius Cestius Epulo, Rabirius, Eurysaces e Caecilia Metella (JOHANSON, 2011, p. 418). efetivo, o estilo Augustano, pois, em seu suporte decorativo, tal como o Ara Pacis, construído entre 13 a 9 a.C., apresenta decorações com guirlandas e cabeça de touro, assim como a relevância da família, em termos simbólicos, como constructo da res publica. O túmulo circular de $30 \mathrm{~m}$ de diâmetro apresenta uma torre com 11 metros de altura (Figura III), uma base quadrada de 7 metros $^{5}$, um corredor que leva à câmara funerária (Figura IV) e na fachada do túmulo (Figura II), a seguinte inscrição: Caeciliae/Q[uinti] Cretici F[iliae]/Metellae Crassi. Sendo uma construção realizada por Crassus, seu esposo, tal como indica o epitáfio, a mensagem privilegia, em nossa percepção, não a imagem da Caecilia Metella, matrona romana, mas a gloria maiorum de sua família, pois como sustenta Rawson (1999, p. 207), no período da República, "a celebração das famílias aparece em grande número nos frisos funerários, marcando, em geral, o status e as ligações com outras famílias".

Como podemos observar, o epitáfio apresenta a linhagem familiar paterna - Caecilia Metella, filha de Quintus Creticus - e a marital, indicando que se uniu em matrimônio com Crassus. Temos, então, a relação de duas famílias aristocráticas que se ajustam à representação do bárbaro em escudo friso, na parte superior do seu túmulo, podendo ser referência, como supõe Carrol (2006, p. 34), à vitória de Marcus Licinius Crassus em 29 ou 28 a.C. na Germânia, Dacia e Moesia. Logo, as imagens das vitórias familiares se complementam à inscrição, transformando, de fato, a história familiar de Caecilia Metella em uma questão pública (CARROL, 2006, p. 34). Conforme esta linha de raciocínio, a localização do mausoléu no alto da Via Appia Antica indica a posição privilegiada da família de Caecilia Metella que, em sincronia, com outras tumbas de famílias aristocráticas, configuravam as relações sociais nos anos finais da República. ${ }^{6}$

Partindo desse contexto, podemos compreender as estruturas extravagantes dos túmulos piramidais, cilíndricos ou os mausoléus (e.g. Augusto construído no Campo de Marte, Caecilia Metella na Via Appia ou Adriano) e suas posiçóes nas necrópoles como indicativos da relevância e da perpetuação de famílias aristocráticas, pois como argumenta Wallace-Hadrill (2008, p. 47), as tumbas e seus epitáfios transformavam-se em 
observatório dos transeuntes e, assim, a família e sua memória ganhavam relevo no espaço público.

\section{MEMÓRIA, LUTO FEMININO E DOR}

Assim como as tumbas e seus epitáfios, responsáveis pela manutenção da memória do morto e de sua família, o discurso filosófico de Sêneca mantém viva a memória de seus mortos, sendo ela, em especial, um trabalho de luto, à medida que se preservava a glória dos heróis, assim como também a perpetuação dos execráveis, transformando a morte consumada em um ato público (BIRREL, 2007, p. 114). Tal como a memória, morrer torna-se, assim, uma ação representativa, como produto social. Percebemos que o filósofo articula a morte à prática da uirtus conferindo-lhe, assim, um sentido especial. Sêneca constrói identidades e orienta, dessa forma, as ações individuais ou coletivas. Isso nos leva a crer que a argumentação de Sêneca enfatiza a morte dos indivíduos num sentido não apenas político, mas, sobretudo, em termos sociais. A normatização das condutas sociais, deste modo, complexa, articula representaçôes distintas no discurso filosófico de Sêneca. Em sua percepção, a dor excessiva não seria um ato natural e, por tal razão, atingiria "mais as mulheres do que os homens, mais os bárbaros do que uma pessoa civilizada, mais um ignorante do que uma pessoa instruída" (Sêneca. Ad Marciam de Consolatione VII. 3). Mulheres aristocráticas, dominadas pelo sofrimento, expressos nos gestos de luto excessivo, tornavam pouco digno seus comportamentos. A manifestação exagerada da dor, atribuída à feminilidade dos ritos tradicionais de luto, em função da morte de um ente querido, revelava uma construção normativa de uma moralidade aristocrática (ERKER, 2011, p. 42).

Em função da conduta memorável de Márcia na corte imperial (Sêneca. Ad Marciam de Consolatione I, 3, 4, 5), Sêneca escreve, aproximadamente em 39 d.C., uma missiva com o objetivo de eliminar seu luto prolongado, e, afastá-la dos comportamentos excessivos, normalmente, atribuídos às mulheres (Sêneca. Ad Marciam de Consolatione VII. 3), pois, de acordo com suas palavras, "importa que, perante o desaparecimento de um amigo, os nossos olhos nem fiquem secos, nem inundados. Chorar, sim, desfazermo-nos em pranto, 
isso não!" (Sêneca. Epistulae Morales 63. 2). Partindo deste contexto, é possível inferir que as representações da morte na consolatória submetiam-se à argumentação, aos exempla e ao conforto, embora, muitas vezes, aparecessem características mais básicas do texto como a delicada questão do tempo, a representação do destinatário e a auctoritas do próprio consolador (KER, 2009, p. 90). Apresentava-se a enunciação do mal com o objetivo de sanar a dor; em seguida, tratava-se da aflição do sujeito, voltando-se para as circunstâncias de sua agonia, e, enfim, concluía-se com alguma resolução reconfortante. Encontram-se, nos textos, temas sobre o valor da vida e, em especial, a aceitação da morte a partir da construção de açōes virtuosas. Como propõe Ker:

A retórica de ocasiáo tornava-se significativa à medida que se cumpria o objetivo terapêutico de eliminação da dor e, em outro nível, o tratamento era mediado por representaçóes culturais e literárias de suas próprias narrativas, que amplificavam o potencial da terapia (KER, 2009, p. 252).

Assim sendo, o filósofo propõe à Márcia, aristocrata romana, reflexões sobre a transgressão praticada por ela no exercício do luto, uma vez que em função da morte do filho Metílio, há três anos, expressava ainda sua dor, afastando-se das atividades cotidianas e mantendo-se isolada no espaço social (Sêneca. Ad Marciam de Consolatione I, 7). O luto feminino devia ser de um ano para a morte do esposo (cf. Sêneca. Epistulae Morales 63. 13; Ovídio. Fasti I, 35-6; Apuleio. Metamorphoseon 8. 7), para a criança menor de três anos não se praticava o luto e as mais velhas não deviam ser lamentadas por mais do que dez meses (ERKER, 2011, p. 54). Era, portanto, considerada uma má conduta feminina estender, em público, o sentimento de dor. A normatização dos prazos para a expressão da dor indica-nos alguns caminhos representativos nas aporias filosóficas de Sêneca, à medida que Márcia, a destinatária da missiva, com características louváveis - matrona exemplar e corajosa - deveria interromper seu luto. É interessante ressaltar as palavras do filósofo:

Mesmo o tempo, que é um remédio natural e acalma até as maiores afliçōes, perdeu a força em seu caso. Três anos se pas- 
saram e nada daquela profunda tristeza abrandou-se: renova-se e fortalece, cotidianamente, a tua dor (Sêneca. Ad Marciam de Consolatione I. 7).

Como se percebe, a aristocrata excede o luto e, ainda mais, expõe seu sentimento de perda e dor; logo, leva-nos a compreender que as representações da morte não expressavam somente o papel público da produção de memória, mas circunscreviam de igual modo dimensōes mais particulares e emocionais da lembrança dos mortos (HOPE b, 2011, p. 177). O sentimento de dor, o grito, a automutilação e a lamentação vão contra os ideais romanos de masculinidade e autocontrole do cidadão, uma vez que essas "emoções fortes" tornavam-se incompatíveis com os ideais de uma vida tranquila (ERKER, 2011, p. 49). Além de condenar o lamento excessivo, o filósofo considerava a morte como indiferente nem boa, nem má - o ideal seria viver com dignidade frente a qualquer acidente da Fortuna, pois, em sua percepção, a morte era um processo (HOPE c, 2009. p. 21), um fim inevitável (Sêneca. Ad Marciam de Consolatione e Ad Paulinum de Brevitate Vitae). Logo, a missiva tornava-se um exercício retórico e filosófico, que permitia a Sêneca exibir os princípios estoicos contra o luto excessivo e prolongado (HOPE c, 2009, p. 134-135).

$\mathrm{Na}$ tentativa de reconfortar Márcia, o filósofo da stoa elabora um discurso que evoca heróis em situaçôes instáveis e perigosas, a exemplo de alguns cidadãos romanos que eram conduzidos à morte voluntária (cf. GRISĖ, 1982; JERPHAGNON, 1985; BROWN, 2001; CONNOLLY, 2009; KER, 2009; HOPE c, 2009; GLENDINNING, 2011, OMENA \& SILVA, 2013, entre outros). Cordo em conflito com Sejano, prefeito da guarda pretoriana (Tácito. Annalium XX$\mathrm{XIV)}$, ridicularizou o decreto que deveria erigir uma estátua em honra daquele, no teatro de Pompeu, reconstruído por César após um incêndio (Sêneca. Ad Marciam de Consolatione XXII, IV). Nas palavras de Sêneca, Cordo, com ironia, exclamou: "que então de verdade perecia o teatro" (Sêneca. Ad Marciam de Consolatione XXII, IV). Tal sarcasmo custou-lhe a vida, suicidando-se por inanição (Sêneca. Ad Marciam de Consolatione XXII, VI). ${ }^{8}$ Seguindo a argumentação de Sêneca, o falecimento de Metílio, se comparado à morte voluntária
8. Pode-se observar esse mesmo exercício cognitivo em Tácito, que acusa a família Júlia-Cláudia de destruir a liberdade em prol de uma nova política de subordinação (Tácito. Annalium I, 1-3). Cordo é acusado em 25 por ter escrito uns Anais que elogiavam Marcus Bruto e, considerava Caio Cássio, o último dos romanos - romanorum ultimum (Tácito. Annalium IV, XXXIV). Em sua defesa, Cordo afirma: "minhas palavras não foram dirigidas nem contra o príncipe, nem contra a mãe do príncipe, o que só é crime de lesa-majestade. Louvei Marco Bruto e Caio Cássio. Suas açôes foram lembradas por muitos escritores, e ninguém sem lhes fazer elogios" (Tácito. Annalium IV, 34) 
9. Em Tito Lívio, Lucrécia manteve a virtude feminina conservando-se casta, após o estupro, por optar pela morte voluntária; logo, tornou-se um modelo de feminilidade doméstica, e sua morte transformou-se em um precedente para outras mulheres, pois, ao que tudo indica, preocupou-se com o papel feminino na construção da república romana (MILNOR, 2009, p. 282-283).

Tácito, contrariamente, elaborou um retrato negativo das mulheres da família imperial (e.g. Messalina, Agripina e Popeia) para criticar suas participaçóes e habilidades no processo de sucessão imperial, evidenciando, desta feita, a atuação do feminino na corte imperial (Tácito. Annalium 4, 53). Consultar bibliografia acerca do debate retórico à época do Principado: CHAPLIN, 2000; EDER, 2005; GEORGE, 2005; GOWING, 2005; DAMON, 2007; FOX, 2007; FELDHERR, 2009; JOSHEL, 2009; SNYDER, 2011; FUNARI, 2011 etc. do avô, seria uma mors opportuna (Sêneca. Ad Marciam de Consolatione XX, 5). Em que pese o fato de ser jovem (Sêneca. Ad Marciam de Consolatione XXIV, 2 e 3), a morte precoce o livrou dos latrocínios públicos, das guerras, dos assassinatos perpetrados contra cidadãos romanos e das condenaçōes ao exílio (Sêneca. Ad Marciam de Consolatione XX, 5). Enfim, a morte o livrou de uma existência miserável (HOPE c, 2009, p. 21).

Nesse sentido, a representação de Cordo na Ad Marciam de Consolatione cumpre, pelo menos, uma importante função social: o filósofo destaca o papel central das mulheres aristocratas - tais como Márcia - que, depois da morte voluntária de Cordo, publicou seus manuscritos, mesmo em condição de censura, e manteve, nas palavras de Sêneca, a eloquentia e a libertas na res publica (Sêneca. Ad Marciam de Consolatione I, 4). Interessa salientar a conduta de Márcia, pois a ação extrapola o espaço doméstico, visto que a incumbência de educar os filhos e gerenciar o lar não se tornam elementos de distinção, mas sim a tarefa de transmitir as ideias de Cordo. Força e coragem convertem-se em símbolos de feminilidade a serem lembrados na comunidade política (MILNOR, 2009, p. 282-283). ${ }^{9}$ Desse modo, tem-se, então, graças à incorporação feminina da uirtus, a recusa de Márcia a dissimular o sofrimento no funeral de seu pai. Frente à tamanha demonstração de coragem, Sêneca a questionou:

Depois que se tornou claro para ti que entre os seguidores de Sejano aquela era a única fuga possível da servidão, não apoiaste a sua decisão, mas reconheceste vencida, e derramaste lágrimas em público e embora tivesses sufocado os lamentos, não os dissimulaste sob um rosto risonho (Sêneca. Ad Marciam de Consolatione I, 2).

Como se percebe, a missiva de Sêneca acentua a ação desmedida de Tibério, e, dessa maneira, destaca a ausência de liberdade republicana a partir do discurso de virtude pessoal (CONNOLLY, 2009, p. 187-188). Temos, sem sombra de dúvida, um padrão moral implícito no discurso, que produz imagens de uma sociedade excessiva e corruptível (Sêneca. De Constantia Sapientis XII, 2); entretanto, o filósofo, a partir desse ambiente de disputas e conflitos, constrói representa- 
ções femininas associadas às virtudes masculinas - força e coragem - à medida que o deslocamento de Márcia simbolizaria a ausência de uirtus masculina e reforçaria, com efeito, a sua presença como força política.

Visto desse modo, Sêneca, ao retomar o discurso sobre as condutas de Otávia e Lívia frente à morte e sua associação com a comunidade política, sugere que tal comportamento deveria também ser mediada pela uirtus, pois, em razão de suas posiçôes sociais, influenciavam a esfera pública. A atenção voltava-se para Lívia, pois a opinião pública - o juiz mais imparcial dos príncipes (Sêneca. Ad Marciam de Consolatione IV, 3) - posicionava-a no espaço público, tornando-a extensão do governo de Augusto. A domus representava a família do passado e do presente, tanto que a paisagem urbana mantinha a presença e a memória do cidadão nas procissões funerárias, criando, dessa forma, um espaço de concorrência entre as famílias (HALES, 2009, p. 55). O que significa que as posiçōes sociais deveriam ser alcançadas e negociadas, sendo visível, no cenário das comemorações funerárias, a ostentação de riquezas e promoções sociais vinculadas a celebrar e prantear o morto (HUSKINSON, 2007, p. 211).

No panorama funerário representado no discurso de Sêneca, prevalece uma imagem visceral de Lívia celebrando o nome do filho, sem ter recolhido o último beijo, "nem a derradeira palavra de sua boca moribunda" (Sêneca. Ad Marciam de Consolatione III, 2) e, mesmo nestas condiçôes, acompanhou, segundo a argumentação do filósofo,

os restos mortais de seu querido Druso durante um longo caminho, abalada, por tantas piras funerárias ardendo por toda a Itália como se por tantas vezes o perdesse; contudo, logo que o depositou no túmulo, depôs, a um tempo, o filho e a sua dor (Sêneca. Ad Marciam de Consolatione III, 2).

A narrativa filosófica acentua o controle emocional da esposa do imperador, e explora a relevância dos ritos funerários como símbolos de prestígio e produção de memória social. Em seu interessante estudo sobre o luto, Erker afirma que "homens e mulheres em luto mudaram seu comportamento do cotidiano, usando roupas de preto, jejuavam, não lavavam os cabelos e negligenciavam o corpo" (ERKER, 2011, 
10. Acrescenta-se a essas discussōes, a festividade da Parentalia que, realizada em fevereiro, representava um momento de agregação e celebração dos mortos, à medida que se comemorava "aniversários como nascimento e morte do falecido, a manutenção de sua tumba e continuidade de seu nome (HOPE a, 2003, p. 117). Tal estudo deve, de modo evidente, ser compreendido a partir de contextos funerários (cf. RAWSON, 1999; CARROL, 2006; HUSKINSON, 2007; FUNARI, 2008; ERKER, 2011; Wallace-Hadrill, 2008; HOPE (b), 2011; NOY, 2011 entre outros mais) ou em narrativas históricas, literárias e filosóficas, quando associadas às representações da morte aos fatores de status, riqueza, gênero, educação e localidade. p. 44). Nesse sentido, o significado e as representações da dor na sociedade romana vinculavam-se aos rituais de luto e, em especial, às suas funções sociais, que, colocavam em relevo, de fato, a ação feminina. Lavar o corpo com água e ungi-lo com óleos perfumados, colocar roupas limpas, cobri-lo com pano branco para o funeral, posicioná-lo no atrium da casa com os pés voltados para a porta da frente, preocupar-se com a queima de incenso, a iluminação com tochas, e, em especial, a purificação do corpo do morto, para assim regulamentar a sua passagem, pois, na sociedade romana, o mundo dos mortos não se misturava com o dos vivos. Tornava-se imprescindível a atuação feminina em prantear o morto, manter-se em luto por um tempo determinado, liberando a familia funesta, pois, em todo o ritual fúnebre, não se podia realizar atividades cotidianas como oferecer sacrifícios aos deuses, participar de atividades públicas e econômicas ou executar qualquer outro ritual (ERKER, 2011, p. 44).

O funeral transformava-se em uma "lembrança ritual" (HOPE a, 2003, p. 115), em atos repetidos, que promoviam o morto e seu passado em diversas circunstâncias, como a produção de imagens do próprio falecido e de seus ancestrais, mantidos e exibidos na casa da família ou nas procissóes funerárias (HOPE a, 2003, p. 116). Isso nos leva a crer que as obrigações sociais do luto - lamentação, canto, dor, gestos de puxar os cabelos, arranhar o rosto até o sangue fluir- eram rituais responsáveis pela conservação da memória do morto (Apuleio. Metamorphoseon 8.7) e, expressavam, de modo efetivo, o caráter social da morte: não se almejava morrer em isolamento, e, sim acompanhado no espaço doméstico por familiares e amigos (cf. Ovídio. Tristium; Sêneca. Epistulae Morales; Suetônio. Augustus); estes estariam preocupados em realizar os ritos de estar à cabeceira, cerrar os olhos, dar o beijo para captar o último suspiro do morto, expor o cadáver no atrium da casa, a inclusão de cenas com gestos dramáticos do sexo feminino, o cumprimento dos pedidos finais, as três conclamaçôes do nome do morto para a realização do funus, acompanhados por aristocratas pela exibição de imagines, máscaras ou retratos em mármore dos antepassados, a realização de banquetes e combates gladiatoriais, indicando, dessa forma, a agregação e celebração da memória do falecido e de seus familiares. ${ }^{10}$ 
Tinha-se, então, a boa morte. Uma morte compartilhada no espaço social (NOY, 2011, p. 01).

A relevância do cerimonial e a capacidade de os enlutados desempenharem papéis sociais nas procissões funerárias aparecem, por exemplo, com muita perspicácia, nas palavras de Ovídio, quando, em situação de exílio, teme uma morte solitária, que seria, em outras palavras, uma morte sem os ritos no leito de morte e sem o consolo de sua esposa. O poeta, frente à impossibilidade de a esposa colocar seu corpo para fora de casa, apresenta uma perspectiva assustadora: morrer em um local desconhecido representava uma exacerbação de sua grave punição (NOY, 2011, p. 04). De acordo com suas lamentações:

Ninguém haverá que me chore depois de morto?

Nem um curto momento sobreviverá a minha alma com as lágrimas da minha esposa caindo em minhas faces?

Não farei recomendaçôes?

A mão amiga não fechará com o último grito meus olhos esvaecidos?

Pois bem a terra estrangeira cobrirá sem funerais, sem a homenagem de um túmulo, este corpo não pranteado? (Ovídio. Tristium III, III, 1, 2, 3).

Morrer em casa implicaria, dependendo das circunstâncias, garantir, como lamenta Ovídio, a prescrição das últimas instruções sobre o patrimônio, questôes associadas ao enterro e haveria, alguém responsável por seus mandata, que certificaria acerca da lucidez da pessoa no momento da morte. $\mathrm{Na}$ arte funerária, por exemplo, o relevo denominado Testamentum, referente à época flaviana, evoca, com grande probabilidade, a presença de um pergaminho, que pode indicar os pedidos finais (NOY, 2011, p. 05). 
11. A figura denominada Testamentum é crédito de Anna Raia (2005), podendo ser consultada na página (http://www.vroma. org/images/raia_images/ sarcophagus_family.jpg).

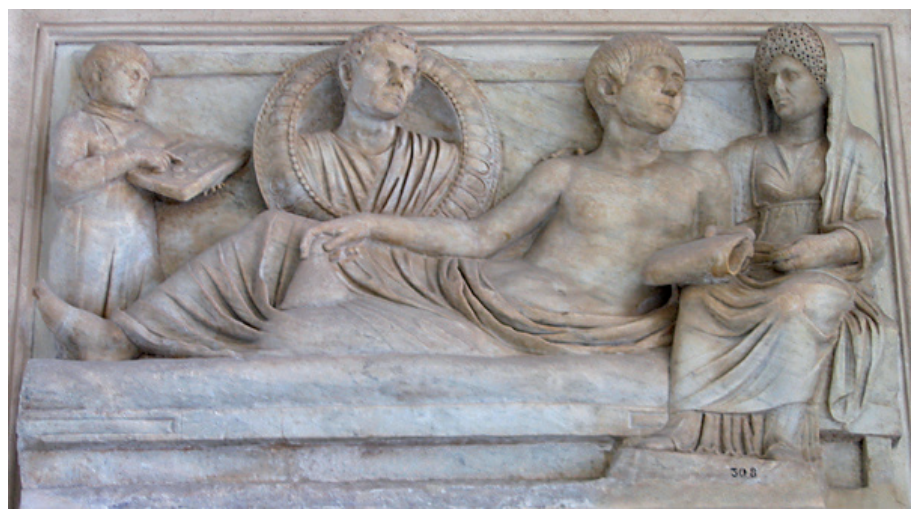

Figura $\mathrm{V}^{11}$

A narrativa apresenta ainda uma figura feminina à cabeceira do jovem falecido, que poderia representar a mãe ou a esposa coberta com um véu, além de uma imago clipeata com a representação do pai morto, sugerindo uma celebração com os ancestrais e, sobretudo, a representação do esquife com os bens pessoais, fornece, como sustenta Noy (2011, p. 05-06), representaçóes de uma boa morte: pacífica, doméstica e com reivindicações de uma continuidade dos laços de afetividade familiares (HOPE b, 2011, p. 181). Nesse sentido, podemos nos aproximar do diálogo imaginário com Lucílio, em especial, à morte voluntária de Marcelino, que, acompanhado por amigos em sua residência, segue a decisão estoica: "morrer com nobreza, com plena consciência e com coragem" (Sêneca. Epistolae Morales 77, 5). Como se percebe, as prescrições dos pedidos finais associavam-se à racionalidade do indivíduo, à capacidade de escolher seu túmulo e de deliberar questôes sobre seu testamento (cf. Petrônio. Satyricon 77) e à sua própria condição social, pois, com muita frequência, a idealização de uma boa morte, conjugava-se, de fato, em compartilhá-la com familiares e amigos. A morte solitária representava o isolamento social, pois, parafraseando Noy (2011, p. 18), as instruçóes práticas não realizadas, o corpo não adequadamente tratado, a ausência da imagem física e do lamento representaria a não preservação de sua memória.

Desse modo, o comportamento de Otávia, que, após a morte do filho, passou, nas palavras do filósofo, "a odiar todas as mães e enfurecia-se, sobretudo com Lívia, porque considerava que a felicidade que a si fora prometida tinha passado 
para o filho dela" (Sêneca. Ad Marciam de Consolatione II, 5), e, por isso, negava-se a participar dos cerimoniais públicos em homenagem a Marcelo. Tal rejeição transformou-se em uma imagem negativa para a potestas de Augusto, pois os cerimoniais, assim como os túmulos, enalteciam o status social do falecido e reconstituíam, dessa forma, a família de Marcelo. A rejeição de Otávia às celebrações da lembrança gloriosa de seu filho representava um esquecimento não somente da memória do morto, mas, de fato, uma destruição da domus de Augusto. Os cortejos fúnebres de Druso e Marcelo revelavam não apenas uma retórica mortuária, mas exprimiam, como produto social, conflitos e tensões na domus de Augusto. A disputa de sucessão entre Otávia e Lívia colocava à primeira em uma situação mais desoladora. O filho morre enquanto Lívia mantém a sucessão imperial com Tibério. $\mathrm{O}$ matrimônio com $\mathrm{Au}$ gusto garantia a Lívia maior espaço de negociação, pois, como acentua Rawson (1992, p. 18), a mãe responsabilizava-se pela criação dos filhos e, assim, adquiria poder e prestígio social com sua família. Lívia incorpora, como esposa, a reputação de guardiã da manutenção e da legitimação da imagem de Augusto (Sêneca. Ad Marciam de Consolatione IV, 3), à medida que a família romana representava uma unidade social e política.

Além dessa associação com a potestas imperial, a rejeição de Otávia marca, sobretudo, o contínuo estágio de luto, deixando o filósofo impressionado com a sua dor: não se consolava, tal como Lívia, com as imagens do filho, recusava-se a possuir qualquer retrato de Marcelo (Sêneca. Ad Marciam de Consolatione I. 7). Neste caso, o retrato de Marcelo, objeto de memória estimado pela enlutada, gerava em Otávia profunda dor. Sêneca utilizou figuras públicas poderosas, Marcelo, Druso, Otávia e Lívia,

para criar oposições literárias e filosóficas associando-as à prática de potestas, definindo, dessa forma, a normatização das condutas públicas de luto. Porém, tudo isso, pelo menos, sugere que retratos, que poderiam ser colocados em contextos públicos e domésticos, tinham poderosas associaçōes como lembretes para os enlutados. Os retratos não eram destinados somente para a construção de identidades públicas aceitáveis para os mortos e os vivos, os retratos e imagens dos 
mortos poderiam ser interpretados como uma forma de mediar e lidar com a dor e com a memória dos mortos (HOPE b, 2011, p. 183).

Nesse sentido, a imagem de Marcelo poderia projetar os valores sociais públicos e os papéis familiares e, mesmo nestas circunstâncias, Otávia, nas palavras de Sêneca, "sepultou-se viva" (Sêneca. Ad Marciam de Consolatione II. 5): "não abandonou o luto das vestes, ofendendo a todos os seus, pois estando eles vivos, ela se considerava sozinha no mundo" (Sêneca. Ad Marciam de Consolatione II. 5). Seguindo essa argumentação, o filósofo associa às representaçôes da morte às dimensões mais particulares e emocionais da lembrança de Marcelo (HOPE b, 2011, p. 177), pois, acometida por intenso sofrimento, Otávia não suporta observar, nem mesmo, suas imagens. Em nosso entender, o comportamento de Otávia explica-se, não somente pelas relações de poder fundamentadas na sucessão imperial, mas também reforça a presença de afetividade nas relaçôes familiares intensificadas com a morte inesperada e prematura de seu filho. Como argumenta Saller (1994, p. 103), a imagem do poder ilimitado dos pais romanos vem reforçada pelos legisladores e não corresponde, de fato, às representações de monumentos iconográficos em que reforça o aspecto familiar através dos retratos do casal com a criança (Ver ainda: SALLER, 1994; ALSTON, 2005; HUSKINSON, 2007, entre outros mais). Os túmulos acentuavam a finitude da vida, promoviam nomes, rostos, identidades, sucessos e, até mesmo, os fracassos dos mortos (HOPE b, 2011, p. 177), entretanto, expressavam, tal como o monumento funerário do filósofo da stoa, a relevância dos laços familiares, mesmo que, em algumas circunstâncias, acentuassem a família como a gloria maiorum, as imagens de afeto circundavam a sociedade imperial.

\section{CONSIDERAÇÕES FINAIS}

A produção de memória social relacionava-se à sociedade romana imperial a partir do aniquilamento do indivíduo e da destruição de sua reputação. A remoção de estátuas e imagens, a exclusão de seu nome nas inscrições públicas, a proibição da recordação da família, à medida que, em algumas 
situações, proibia-se o luto e a exposição de sua imagem em futuros funerais da família e, em especial, o luto excessivo atribuído às mulheres, poderiam conduzir, homens e mulheres, à sua eliminação social. Deste modo, tornava-se imprescindível construir imagens vinculadas à produção de um passado, que orientaria o presente a partir da criação dos exempla, pois, na percepção filosófica, as açôes passadas poderiam se reproduzir no presente. Nesse sentido, o filósofo da stoa compreendia que pertencer e participar da sociedade implicaria, com efeito, em criar normas de comportamento do cidadão - frente à política, à familia e, em especial, aos domínios da morte - em um ethos aristocrático e, sobretudo, masculino fundamentado no autocontrole do indivíduo. O logos filosófico de Sêneca produz, dessa forma, imagens de heróis romanos - Cordo, Márcia e Lívia - como recurso retórico para produzir uma memória que acentue a ação social em torno da prática da uirtus. Com isso, a narrativa priorizou a incorporação da uirtus masculina a ser exercida pelas mulheres, que, presentes no espaço público, tornavam-se fonte de influência na política imperial.

\section{AgradeCimentos}

Agradecemos a Pedro Paulo A. Funari pela leitura e sugestōes. Somos gratas também a Darío N. Sánchez Vendramini (Universidad Nacional de la Rioja), Ana Teresa Marques Gonçalves (UFG) e Graciela Gómez (Universidad Católica Argentina (UCA)) pela troca de ideias. No entanto, as reflexões desenvolvidas no decorrer do artigo são de responsabilidade das autoras.

\section{REFERÊNCIAS BIBLIOGRÁFICAS}

\section{a) Documentos textuais}

APULÉE. Les Métamorphoses. Traduit par P. Vallette. Paris: Les Belles Lettres, 2002.

LIVIO, Tito. Histoire Romaine. Tome I - Livre I. Texte établi par Jean Bayet e traduit par Gaston Baillet. Paris: Société d'Édition "Les Belles Letres" 1947.

OVID. Tristium. Translation by Arthur Leslie Wheeler. London: The Loeb Classical Library, 1939. 
. Fasti. Translation by James George Frazer.

London: Willlam Heinemann, 1989.

PETRÔNIO. Satíricon. Trad. Cláudio Aquati. São Paulo: Cosac Naify, 2008.

SÉNÈQUE, L. A.. Consolations (Tome III). In: Dialogues. Trad. par René Waltz. Paris: Les Belles Lettres, 1923. . Lettres a Lucilius (Tome I). Trad. par

MM. A.Grandsagne; Baillard, Charpentier, Cabaret-Dupaty ; Charles du Razoir; Héron de Villefosse ; Naudet, C. L. F. Panckoucke, E. Panckoucke; De Vatimesnil, A. De Wailly etc. Paris: Les Belles Lettres, 1833.

. Lettres a Lucilius (Tome VI/VII). Trad. par MM. A.Grandsagne; Baillard, Charpentier, Cabaret-Dupaty ; Charles du Razoir; Héron de Villefosse ; Naudet, C. L. F. Panckoucke, E. Panckoucke ; De Vatimesnil, A. De Wailly etc. Paris: Les Belles Lettres, 1834.

. De la brièveté de la vie. (Tome II).

In: Dialogues. Trad. par A. Bourgery. Paris: Les Belles Lettres, 1955.

SUETONIUS. The lives of the Caesars (vol. I). Translated by J. C. Rolfe. London: Loeb Classical Library, 1979.

TACITUS. Annals. Translated by A. J. Woodman. Cambridge: Hackett Publishing Company, Inc., 2004.

\section{b) Obras gerais}

ALSTON, Richard. Searching for the Romano-Egyptian Family. In: GEORGE, Michele (ed.). The Roman Family in the Empire: Rome, Italy and beyond. Oxford: Oxford University Press, 2005. p. 129-158.

ASSMANN, Jan. Historia y mito em el mundo antiguo. Los Origenes culturales de Egipto, Israel e Grecia. Trad. de Ambrosio Berasain Villanueva. Madrid: Editorial Gredos, 2011.

BIRREL, Ross. O presente do terror: o ataque suicida como Potlatch. In: GREINER, Christine; AMORIN, Cláudia (orgs.). Leituras da Morte. São Paulo: Annablume, 2007, p. 105-127.

BOATWRIGHT, Mary T.. Children and parents on the Tombstones of Pannonia. In: GEORGIE, MICHELLE 
(org.). The roman family in the empire. Oxford; Oxford University Press, 2005, p. 287-300.

BROWN, Ron M. The art of suicide. London: Reaktion Books, 2001.

CARROL, Maureen. Roman funerary commemoration in western. Oxford: Oxford University Press, 2006.

CHAPLIN, Jane D. Livy's exemplary history. Oxford: Oxford University Press, 2000.

CONNOLLY, JOY. Virtue and violence: the historians on politics. In: FELDHERR, Andrew. The Roman historians. Cambridge: Cambridge University Press, 2009, p. 181-194.

DAMON, Cynthia. Rhetoric and Historiography. In: DOMINIK, William. HALL, Jon (ed.). A companion to Roman Rhetoric. Oxford: Blackwell, 2007, p.439-450.

DIXON, Susan. The Roman Family. Londres: The John Hopkins University Press, 1992.

ECKARDT, Hella; WILLIAMS, Howard. Objects without a past? The use of Roman objects in early Anglo-Saxon graves. In: WILLIANS, Howard. Archaeologies of remembrance. New York: KalPP, 2003, p. 141-170.

EDER, Walter. Augustus and the Power of Tradition. In: GALINSKY, Karl (ed.). The Cambridge Companion to the Age of Augustus. Cambridge: Cambridge University Press, 2005, p. 13-32.

ERKER, Darja Sterbenc. Gender and roman funeral ritual. In: HOPE, Valerie M.; HUSKINSON, Janet (orgs.). Memory and Mourning: Studies on Roman Death. Oxford: Oxbow Books, 2011, p. 40-60.

FELDHERR, Andrew. The roman historians. Cambridge: Cambridge University Press, 2009.

FOX. Matthew. Rhetoric and literature at Rome. In: DOMINIK, William and HALL, Jon (ed.). A companion to Roman Rhetoric. Oxford: Blackwell, 2007, p.369-381.

FUNARI, P. P. A.. A diversidade de concepções sobre a morte e a magia: uma abordagem antropológica. In: BUSTAMANTE, R. C. (org.). Vida, morte e magia no mundo antigo. Rio de Janeiro: NEAIUERJ, 2008, p. 68-74. 
. Ensaio sobre a retórica, a argumentação e

a historiografia antiga. Revista Eletrônica Antiguidade Clássica 7, no 1, p. 140-149, 2011.

GAGNEBIN, Jeanne Marie. Lembrar, escrever, esquecer. São Paulo: Editora 34, 2006.

GEORGE, Michele. Family Imagery and Family Values in Roman Italy. In: GEORGE, Michele (ed.). The Roman Family in the Empire: Rome, Italy and beyond. Oxford: Oxford University Press, 2005. p. 37-66.

GLENDINNING, Eleanor Ruth. Guilt, Redemption and Reception: Representing Roman Female Suicide. University of Nottingham: University of Nottingham, 2011.

GRISĖ, Yolande. Le suicide dans la Rome antique. Paris: Les Belles Lettres, 1982.

GOWING, Alain M. Empire and memory: the representation of the Roman Republic in imperial culture. Cambridge: Cambridge University Press, 2005.

GUNDERSON, Erik . Fathers and sons; bodies and pieces. In: Declamation, Paternity and roman identity. Cambridge: Cambridge University Press, 2003, p. 59-89.

HALES, Shelley. The house and the construction of memory. In: HALES, Shelley. The Roman house and social identity. Cambridge: University Press Cambridge, 2009, p. 40-60.

HUSKINSON, Janet. Constructing childhood on roman funerary memorials. Hesperia Supplements, vol. 41, Italy, 2007, p. 323-338.

HOPE, Valerie M.. Remembering to mourn personal mementos of the dead in Ancient Rome. In: HOPE, Valerie M.; HUSKINSON, Janet (orgs.). Memory and Mourning: Studies on Roman Death. Oxford: Oxbow Books, 2011b, p. 176-195.

. Roman Death: the Dying and the Dead in Ancient Rome. New York: Continuum, 2009c.

. Remembering Rome. Memory, funerary monuments and the Roman soldier. In: WILLIANS, Howard. Archaeologies of remembrance. New York: KalPP, 2003a, p. 113-140. JERPHAGNON, Lucien. Le suicide dans la Rome antique. Revue Belge de Philologie et d'Historie, Annèe, v. 63, n. 1. p. $149-151,1985$. 
JOHANSON, Christopher. A walk with the dead: a funerary cityscape of ancient Rome. In: RAWSON, Beryl A. Companion to families in the Greek and Roman worlds. Oxford: Library of Congress, 2011, p. 408-430.

JOSHEL, S. R. The Body female and the body politic: Livy's Lucretia and Verginia. In: CHAPLIN, Jane D. and KRAUS, Christina S. Oxford readings in classical studies Livy. Oxford: Oxford, 2009, p. 380-408.

KER, James. The deaths of Seneca. Oxford: University Press, 2009.

KING, Margaret. Commemoration of infants on roman funerary. In: OLIVER, G. J.. The epigraphy of death. Studies in the history and society of Greece and Rome. Liverpool: Liverpool University Press, 2000, p. 117-154.

MILNOR, Kristina. Women in Roman historiography. In: FELDHERR, Andrew. The Roman historians. Cambridge: Cambridge University Press, 2009, p. 276-287.

NOY, David. Goodbye Livia's: dying in the roman home. In: HOPE, Valerie M.; HUSKINSON, Janet (orgs.). Memory and Mourning: Studies on Roman Death. Oxford: Oxbow Books, 2011, p. 01-20.

OMENA, Luciane M. de; SILVA, Suiany Bueno. A retórica da morte na narrativa de Tito Lívio (Século I a.C.). Revista História e Cultura, Franca-SP, v. 2, n. 3 (Especial), p. 94-108, 2013.

OMENA, Luciane M. de; FUNARI, Pedro P. A.. Memória e esquecimento: narrativa sobre imperador romano e senado. História, v. 31, n. 01, p. 163\184, já.ljun., 2012.

PATTERSON, J. R.. On the margins of the city of Rome. In: HOPE, V.; Marshall, E. Death and disease in the Ancient city. London and New York: Routledge, 2000, p. 85-103.

RAWSON, Beryl. The Roman family. In: RAWSON, Beryl. The family in ancient Rome. New perspective. Ithaca, New York: Cornell University Press, 1992, p. 01-57.

. The iconography of Roman Childhood. In: RAWSON, Berly; WEAVER, Paul. The roman in family: status, sentiment, space. Oxford: Oxford University Press, 1999, p. 205-232. 
ROLLER, Matthew. The exemplary past in Roman historiography and culture. In: The roman historians. Cambridge: Cambridge University Press, 2009, p. 181-194.

SALLER, Richard P. Patriarchy, property and death in the Roman family. Cambridge: Cambridge Studies in Population, Economy and Society in Past Time, 1994.

SNYDER, Ellen.Virtue, Violence, and Victors: The Role of Pudicitia in Livy's Ab Urbe Condita. UCLA Center for the Study of Women. 2011, p. 1-8.

VERNANT, Jean-Pierre. El individuo, la muerte y el amor en la antigua Grecia. México, Buenos Aires e Barcelona: Paidós, 2001.

WALLACE-HADRILL, Andrew. Housing the Dead: The Tomb as House in Roman Italy. In: BRINK, Laurie; GREEN, Deborah (eds.). Commemorating the Dead: Texts and Artifacts in Context. New York: Walter de Gruyter, 2008, p. 39-77.

YÉBENES, Sabino Perea. In bello desideratis. Estética y percepción de la muerte del soldado romano caído en combate. In: SIMÒN, F. M.; POLO, F. P.; RODRÍGUEZ, J. R. (org.). Formae mortis: el tránsito de la vida a la muerte en las sociedades antiguas. Barcelona: Universitat de Barcelona, 2009, p. 39-88.

Recebido em março de 2014. Aprovado em julho de 2014. 